\title{
Perceived Parental Control and Disclosure of Adolescents with Disciplinary Problems
}

\author{
Zarinah Arshat ${ }^{1} \&$ Ang Chun $\mathrm{Ee}^{1}$ \\ ${ }^{1}$ Department of Human Development and Family Studies, Faculty of Human Ecology, Universiti Putra Malaysia, \\ Malaysia \\ Correspondence: Zarinah Arshat, Department of Human Development and Family Studies, Faculty of Human \\ Ecology, Universiti Putra Malaysia, 43400 UPM Serdang, Selangor Darul Ehsan, Malaysia. Tel: 603-8946-7139. \\ E-mail: zarinah_upm@upm.edu.my
}

Received: February 21, 2017

doi:10.5539/ass.v13n11p42
Accepted: March 24, 2017 Online Published: October 28, 2017

URL: https://doi.org/10.5539/ass.v13n11p42

\begin{abstract}
Disciplinary violation are commonly found among school-going adolescents. The current study examined the relationship between parental control and disclosure among adolescents with disciplinary problems. A total of 354 adolescents were recruited using multistage cluster random sampling technique in Selangor. Results from the correlational analysis revealed that the higher the paternal and maternal control on adolescents, the higher the adolescents' disclosure to their father and mother. This suggests that prevention strategies focusing on parental control in relation to disclosure is applicable to adolescents with disciplinary problems.
\end{abstract}

Keywords: paternal control, maternal control, adolescents disclosure, disciplinary problems

\section{Introduction}

Disciplinary problem remains a major problem involving by adolescents. Disciplinary problem is different from juvenile and delinquent acts. It is not categorized as an offence in the penal code even though it is considered as a serious social problem (Bates \& Pettit, 2007). The Ministry of Education in Malaysia (2013) recorded 3.43\% of discipline problem in the total number of secondary student enrolments. Ministry of Education in Malaysia had developed a system in year 2008, namely Web-Based Student Discipline System to record secondary school students' disciplinary problem. The disciplinary problems listed in the system include criminal acts, substance use, bullying, smoking, truancy, pornographic related behaviour, impolite act, vandalism, integrity issue and naughtiness. The system records the details of disciplinary violation of students and actions taken on them, such as the number of warning letters issued, parent-teacher meetings as well as counselling sessions

The interaction between adolescents and parents is dynamic and change across the developmental stage. Adolescents started to detach from their parents as they required for more autonomy. When the time spent with parents became less, parents could not get information about adolescents' where-about. Adolescent is the source of information to parents (Crouter \& Head, 2002). Parents were predicted to solicit more as the time adolescents spent with family became lesser compared to their childhood (Stattin \& Kerr, 2000). In addition, parents exercised control on their adolescent to ensure adolescent where-about and to keep them informed as parents had less time with their adolescents (Stattin \& Kerr, 2000). Although parental solicitation and control have good intention, adolescents might perceived it differently. Parents' effort to get updated about adolescents' where-about could be done through parental control. Adolescents' willingness to disclose to parents is influenced by positive parental behavior, such as supportive and concern to adolescent (Hazen, Schlozman, \& Beresin, 2008).

Parental disclosure is often related to parents' active tracking (Kerr \& Stattin, 2000). Different parental control from parents resulted in different influences. For instance, high behavioural control led to more voluntarily disclosure to parents and psychological control was negatively related to adolescent's disclosure (Soenens et al., 2007). Behavioural control is the parents' effort to constrain their children's behaviour and psychological control is the attempt by parents to control children's emotional state. Parental psychological control is viewed as more intrusive and has led to lesser voluntary disclosure from adolescent. Psychological control from parents was reported to associate with greater disclosure from 9th and 12th grader adolescents who grew up in lower middle class families (Smetana, Metzger, Gettman, \& Campione-Barr, 2006). 
Disclosure from adolescents is their own choice. Adolescent tend to reduce urge to voluntarily disclose to their parents as adolescent perceived their parents as no longer treating them as children but as adults. There were contradiction between parental control and adolescents' perception on parental control issue. Girls reported that parents employed more control over them compared to boys (Domenech Rodríguez, Donovick, \& Crowley, 2009). However, parents reported that they controlled their boy adolescents more than they did their girls (Endendijk, Groeneveld, Bakermans-Kranenburg, \& Mesman, 2016; Stattin \& Kerr, 2000). As discussed in the literature review above, this study attempts to examine the relationship between adolescents and family characteristics with parental control and also relationship between parental control and disclosure among adolescents with disciplinary problems.

\section{Research Methodology}

\subsection{Participants}

There were 354 adolescents with disciplinary problems involved in this study. The adolescents were aged between 13 to 18 years old $(\mathrm{M}=15.96$ years old, $\mathrm{SD}=1.24)$ who residing in three selected district in Selangor. The present study utilized multistage cluster sampling technique to recruit the participants. Most of them were male adolescents $(62.3 \%)$. On top of it, there were $48.2 \%$ of adolescents were from low socioeconomic families, where their reported family monthly income is lesser than RM2500 $(\mathrm{M}=\mathrm{RM} 2239.87, \mathrm{SD}=1706.34)$. Adolescents who participated in the present study have $87.5 \%$ of father $(\mathrm{M}=47.6$ years old, $\mathrm{SD}=6.62)$ and $92.6 \%$ of mother $(\mathrm{M}=44.0$ years old, $\mathrm{SD}=5.34)$ aged between 36 through 55 years old.

\subsection{Procedure}

Prior to data collection permission from Ministry of Education Malaysia, Selangor Educational Department, Ethics Committee for Research involving Human Subjects of Universiti Putra Malaysia (JKEUPM), and school principals were approved. In this study only adolescents who had their name on school's disciplinary record were eligible to be the sample. Disciplinary record is a list with the name of adolescents who go against school rules. The school rule is a set of regulation outline from the Ministry of Education framework on problematic behaviors. This procedure was to make sure sample recruited for the present study fulfilled the criterion of disciplinary problem. Adolescents respond to the questionnaire after being briefed about the issue being focused in the present study as well as private and confidential issues in the classroom. Adolescents handed-in back the completed questionnaire to the researcher before leaving the classroom.

\subsection{Measures}

\subsubsection{Parental Control}

Parental Control Questionnaire (Kerr \& Stattin, 2000) was used to assess adolescent perception towards the amount of both mother and father supervision asserted on them. The are 6-item with 5-point likert scale ranging from 1 (never) to 5 (always). The example of questions are "Must you ask your parents before you can make plans with friends about what you will do on a saturday night?" and "Do your parents demand that they know where you are in the evenings, who you are going to be with, and what you are going to do?". The reliability for this scale for father is 0.89 and mother is .83 .

\subsubsection{Adolescents Disclosure}

Adolescent's disclosure was measured using Adolescent Disclosure Questionnaire (Smetana et al., 2006). Adolescents are response to each of the 12 items in the scale on a five-point scale ranging from $1=$ never tell to $5=$ always tell. The scale has three dimensions namely prudential issue, personal issues and multifaceted issues. Example of the items are "How often do you usually or are willing to tell your mother and father, without she or he asking about", "Hanging out at a friend's when no adult is home" and "How you spend your own money". The reliability for this scale in this study for disclosure to father is 0.93 and mother is .92 .

\section{Results and Discussion}

\subsection{Relationship between adolescent characteristics and parental control}

Results presented in Table 1 were the correlation coefficient between adolescent characteristics and parental control. First, adolescent's age is found to have significant negative relationship with paternal control $(r=-0.25$, $p<0.01)$ and negative relationship with maternal control $(r=-0.34, p<0.01)$. These results illustrated that as adolescent grow older, both of their father and mother control them lesser. The result was parallel with the finding in Keijsers at al. (2009) which revealed declination in parents control at the age 13 through 16 years old and study by Endendijk et al. (2016) that found controlling strategies was larger for younger children than for older children. It is vital for parents to find out a balancing point between letting go their adolescence and hold 
tight to their control. Adolescence turned mature in their cognitive development, which covering inhibitory control (Ashford \& LeCrog, 2009), decision making (Conklin, Hooper, \& Yarger, 2005) and more aspects during adolescence and persists as they grew older and by time, parents were more likely to grant adolescence for more autonomy over their own life. In this case, adolescents with discipline problem would probably reduce in frequency or severity as age increased. Followed by then, parental control shall reduce as well.

Then, sex reported to have significant positive relationship with adolescent perceived paternal control $(r=0.40$, $p<0.01)$ and maternal control $(r=0.41, p<0.01)$. In another word, female adolescents reported that both father and mother control them more than the boys. Parents tend to assert control in regulating adolescence behavior with promising better adolescent functioning (Bean, Barber \& Crane, 2006). To be take note that girls are more likely to be at risk being sexually victimization besides general internalizing and externalizing problems (Perilloux, Fleischman, \& Buss, 2011). In addition, discipline problem in boys often viewed as normal naughty but it is another case when applied on the girls. Discipline problem among girls adolescent perceived to be a serious matter (Timimi, 2005). Hence, parents asserted more controlling power as well as more limitation to regulate their girl adolescent behavior compared to boys.

Parents' controlling effort is a limitation in order to regulate on adolescents behavior. Although there was finding in Malaysia indicated that parents control differently based on the birth order of their children (Ng, Mofrad \& Uba, 2014), but it was interesting to know that number of siblings have no significant association on both paternal and maternal control. However, the participants in present study have discipline problem background. The results discovered in present study could explain adolescents with discipline problem are probably sensitive towards the controlling effort from parents and tend to exaggerate it like their parents control on them.

Table 1. Relationship between adolescent characteristics and family characteristics with parental control

\begin{tabular}{|c|c|c|}
\hline \multirow[t]{2}{*}{ Variables } & \multicolumn{2}{|c|}{$r(p)$} \\
\hline & Paternal control & Maternal control \\
\hline \multicolumn{3}{|l|}{ Adolescent Characteristics } \\
\hline Age & $-.25(.00)^{* *}$ & $-.34(.00)^{* *}$ \\
\hline Sex & $.40(.00)^{* *}$ & $.41(.00)^{* *}$ \\
\hline Number of siblings & $-.08(.16)$ & $-.04(.11)$ \\
\hline \multicolumn{3}{|l|}{ Family Characteristics } \\
\hline Father age & $-.12(.02)^{*}$ & \\
\hline Mother age & & $-.17(.00)^{* *}$ \\
\hline Father education level & $.08(.31)$ & \\
\hline Mother education level & & $.04(.41)$ \\
\hline Family monthly income & $-.05(.12)$ & $.02(.25)$ \\
\hline
\end{tabular}

Note: $* p<.05, * * p<.01$

\subsection{Relationship between family characteristics and parental control}

As for family background characteristics, adolescent's father age had significant negative relationship with paternal control $(r=-0.12, p<0.05)$. On top of it, mother's age also found to have significant association with maternal control negatively $(r=-0.17, p<0.01)$. In another words, older father and mother exercised less controlling behaviors on their adolescence. Wang, Bianchi, and Raley (2005) explained that there was continuous evolution in the parents' role in the association on parental control level as parents' age increase. Malaysian parents recognized the needs for adolescence to develop independency but they were a little fall back compared to the global developmental milestone (Keshavarz \& Baharuddin, 2009). Thus, parents become more lenient to adolescents as parents' age increase. In addition, accumulation of life experiences followed by the increment of age changed parents' way to show their concern toward adolescent (Nixon \& Halpenny, 2010), which parents were discovered to lessen control on adolescence in present study.

In addition, parents' educational level reported to have no significant relationship with parental control and maternal control. Although Elias and Tan (2009) speculated that higher parents' education level increase the parents' exposure to negative outcome of authoritarian parenting and reduce it for better development of their children. Authoritarian parenting is about power asserting on their children and it shared common characteristic with parental control measured in present study. But findings of present study did not support the saying. Similarly, family monthly income also reported to has no significant relationship with parental control due to 
Malaysian parents preferable to raise their children using the way their parents' apply on them.

\subsection{Relationship between parental control and adolescent disclosure}

According to Table 2, paternal control was found to positively significant correlate with disclosure to father $(r=0.52, p<0.01)$. There was also significant positive relationship between maternal control and disclosure to mother $(r=0.51, p<0.01)$. It indicated that higher control from father and mother on adolescence associated with adolescence voluntarily disclosure to father and mother.

Parental control has significant contribution to disclosure among adolescent with discipline problem. Parental control is about rules setting from parents towards adolescent in promising their positive development. Adolescent behavior became restricted when their parents placed control on them (Mehra, Savithi, \& Coutinho, 2002). Hence, parental control was associated with adolescents disclosure as adolescents have lesser to hide from parents about their discipline related activities (Keijsers et al., 2009)

Table 2. Relationship between parental control and adolescent disclosure to parents

\begin{tabular}{ccc}
\hline Variables & $\begin{array}{c}\text { Disclosure to father } \\
\mathrm{r}(\mathrm{p})\end{array}$ & $\begin{array}{c}\text { Disclosure to mother } \\
\mathrm{r}(\mathrm{p})\end{array}$ \\
\hline $\begin{array}{c}\text { Paternal control } \\
\text { Maternal control }\end{array}$ & $.52(.00)^{* *}$ & $.51(.00)^{* *}$ \\
\hline
\end{tabular}

Note: $* * p<.01$

\section{Conclusion and Recommendation}

The present study found several associations between adolescents and family characteristics and parental control. As for adolescents characteristics, the finding showed that adolescent's age has negative relationship with both paternal and maternal control. In other words, younger adolescents perceived that their father and mother asserted more control on them. In this study female adolescents perceived that their father and mother control them more compared to male adolescents. While for family characteristics, the present study found that adolescents with younger aged parents perceived that their mother and father control more. The result revealed that adolescents with disciplinary problems who perceived to experience high level of parental control were more willing to disclose about themselves to parents.

Some limitations of the present study should also be noted. The first limitation for the present study is the small sample size. Small sample size the generalizability of the findings to the intended population. It is recommended future study to consider on larger geographic areas in the effort to generalize the findings on Malaysia adolescence with disciplinary problems. Second, data collection of current study was depended highly on the level of honesty of the respondents in answering the self-administered questionnaires. Response bias happened all the time when the data are gathered from self-reported questionnaire where respondents tend to choose the answer that seems correct or appropriate, some respondents even choose the answer without really read. Thus, future studies have to use different methods to collect data in order to reduce the dishonesty response. Lastly, this study only focused on two variables only (i.e. parental control and adolescent disclosure). So, any future studies carried out will require a more in-depth look other variables that may influence adolescents disclosure to their parents such as parental knowledge, parental solicitation and parent-child relationship.

\section{References}

Ashford, J. B. \& LeCroy, C. W. (2009). Decision-making for juvenile offenders in aftercare. Juvenile and Family Court Journal, 39(1), 47-53. https://doi.org/10.1111/j.1755-6988.1988.tb00611.x

Bates, J. E. \& Pettit, G. S. (2007). Temperament, parenting, and socialization. In J. E. Grusec \& P. D. Hastngs (Eds.), Handbook of socialization: Theory and research (pp. 153-177). New York: Guilford Press.

Bean, R. A., Barber, B. K., \& Crane, R. D. (2006). Parental support, behavioral control, and psychological control among African American youth: The relationships to academic grades, delinquency, and depression. Journal of Family Issues, 27(10), 1335-1355. https://doi.org/10.1177/0192513X06289649

Crouter, A. C. \& Head, M. R. (2002). Parental monitoring and knowledge of children. In Bornstein, M. H. (Ed.), Handbook of Parenting. (pp. 461-484). Mahwah, NJ: Lawrence Earlbaum Associates Inc.

Domenech Rodríguez, M. M., Donovick, M. R., \& Crowley, S. L. (2009). Parenting styles in a cultural context: Observations of 'protective parenting' in first-generation Latinos. Family Process, 48, 195-210. https://doi.org/10.1111/j.1545-5300.2009.01277.x 
Elias, H., \& Tan, H. Y. (2009). Relationship between perceived paternal and maternal parenting styles and student academic achievement in selected secondary schools. European Journal of Social Sciences, 9, 181-192. Retrieved from http://www.eurojournals.com/ejss_9_2_01.pdf

Endendijk, J. J., Groeneveld, M. G., Bakermans-Kranenburg, M. J., \& Mesman, J. (2016). Gender-differentiated parenting revisited: Meta-analysis reveals very few differences in parental control of boys and girls. PLoS One, 11(7), 1-33. https://doi.org/10.1371/journal.pone.0159193

Hazen, E., Schlozman, S., \& Beresin, E. (2008). Adolescent psychological development: A review. Pediatrics in Review, 29(5), 161-168. https://doi.org/10.1542/pir.29-5-161

Kerr, M., \& Stattin, H. (2000). What parents know, how they know it, and several forms of adolescent adjustment: Further support for a reinterpretation of monitoring. Developmental Psychology, 36(3), 366-380. https://doi.org/10.1037/0012-1649.36.3.366

Keshavarz, S., \& Baharudin, R. (2009). Parenting style in a collectivist culture of Malaysia. European Journal of Social Science, 10(1), 66-73. Retrieved from https://www.researchgate.net/publication/283832677_ Parenting_style_in_a_collectivist_culture_of_Malaysia

Luciana, M., Conklin H. M., Hooper, C. J., \& Yarger, R. S. (2005). The development of nonverbal working memory and executive control processes in adolescents. Child Development, 76(3), 697-712. https://doi.org/10.1111/j.1467-8624.2005.00872.x

Mehra, S., Savithri, R., \& Coutinho, L. (2002). Sexual behaviours among unmarried adolescents in Delhi, India: Opportunities despite parental controls. Article presented at the 2002 IUSSP Regional Population Conference on Southeast Asia's Population in a Changing Asian Context; Bangkok, Thailand. June 2002. Retrieved from http://archive.iussp.org/Bangkok2002/S30Mehra.pdf

Ng, W. L., Mofrad, S., \& Uba, I. (2014). Effect of birth order on the differential parental treatment of children. Asian Social Science, 10(14), 168-178. https://doi.org/10.5539/ass.v10n14p132

Nixon, E., \& Halpenny, A. M. (2010). Children's Perspectives on Parenting Styles and Discipline: A Developmental Approach. Dublin: Office of the Minister for Children and Youth Affairs. Retrieved from https://www.tcd.ie/childrensresearchcentre/assets/pdf/Publications/Children's_perspectives_on_parenting_st yles.pdf

Perilloux, C., Fleischman, D. S., \& Buss, D. M. (2011). Meet the parents: parent-offspring convergence and divergence in mate preferences. Personality and Individual Differences, 50, 253-258. https://doi.org/10:1016/j.paid.2010-09-039

Smetana, J. G., Metzger, A., Gettman, D. C., \& Campione-Barr, N. (2006). Disclosure and secrecy in $\begin{array}{lllll}\text { adolescent-parent } & \text { relationships. } & \text { Child } & \text { Development, } & \text { 77(1), }\end{array}$ https://doi.org/10.1111/j.1467-8624.2006.00865.x

Soenens, B., Vansteenkiste, M., Lens, W., Luyckx, K., ... Ryan, R. M. (2007). Conceptualizing parental autonomy support: Adolescent perceptions of promoting independence versus promoting volitional functioning. Developmental Psychology, 43(3), 633-646. https://doi.org/10.1037/0012-1649.43.3.633

Stattin, H., \& Kerr, M. (2000). Parental monitoring: A reinterpretation. Child Development, 71(4), 1072-1085. https://doi.org/10.1111/1467-8624.00210

Timimi, S. (2005). Naughty boys: Anti-social Behavior, ADHD and role of culture. Basingstoke: Palgrave Macmillan.

Wang, R., Bianchi, S., \& Raley, S. (2005). Teenagers' internet use and family rules: A research note. Journal of Marriage and Family, 67, 1249-1258. https://doi.org/10.1111/j.1741-3737.2005.00214.x

\section{Copyrights}

Copyright for this article is retained by the author(s), with first publication rights granted to the journal.

This is an open-access article distributed under the terms and conditions of the Creative Commons Attribution license (http://creativecommons.org/licenses/by/4.0/). 